\title{
Molecular Mapping of Stripe Rust Resistance Gene Yr81 in a Common Wheat Landrace Aus27430
}

\author{
Mesfin Gessese, ${ }^{1}$ Harbans Bariana, ${ }^{1}$ Debbie Wong, ${ }^{2}$ Matthew Hayden, ${ }^{2,3}$ and Urmil Bansal ${ }^{1, \dagger}$ \\ ${ }^{1}$ The University of Sydney Plant Breeding Institute, School of Life and Environment Sciences, Faculty of Science, Cobbitty, \\ NSW 2570, Australia; ${ }^{2}$ Agriculture Victoria Research, Department of Economic Development, Jobs, Transport and Resources, \\ AgriBio, Bundoora, VIC 3083, Australia; and ${ }^{3}$ School of Applied Systems Biology, La Trobe University, Bundoora, VIC 3083, \\ Australia
}

\begin{abstract}
The deployment of diverse sources of resistance in new cultivars underpins durable control of rust diseases. Aus27430 exhibited a moderate level of stripe rust resistance against Puccinia striiformis f. sp. tritici (Pst) pathotypes currently prevalent in Australia. Aus27430 was crossed with the susceptible parent Avocet S (AvS) and subsequent filial generations were raised. Monogenic segregation observed among Aus27430/AvS $\mathrm{F}_{3}$ families was confirmed through stripe rust screening of an $\mathrm{F}_{6}$ recombinant inbred line (RIL) population, and the resistance locus was temporarily named $\mathrm{YrAW5}$. Selective genotyping using an Illumina iSelect $90 \mathrm{~K}$ wheat SNP bead chip array located YrAW5 in chromosome 6A. Genetic mapping of the RIL population with linked 90K SNPs that were converted into PCR-based marker assays, as well

as SSR markers previously mapped to chromosome 6A, confirmed the chromosomal assignment for YrAW5. Comparative analysis of other stripe rust resistance genes located in chromosome 6A led to the formal designation of $Y r A W 5$ as $Y r 81$. Tests with a marker linked with $\operatorname{Yr} 18$ also demonstrated the presence of this gene in Aus27430. Yr18 interacted with $\operatorname{Yr} 81$ to produce stripe rust responses lower than those produced by RILs carrying these genes individually. Although gwm459 showed higher recombination with $\operatorname{Yr} 81$ compared with the other flanking marker KASP_3077, it amplified the AvS allele in 80 cultivars, whereas KASP_3077 amplified AvS allele in 67 cultivars. Both markers can be used in marker-assisted selection after confirming parental polymorphism.
\end{abstract}

The concept of genome mapping dates back to the landmark publication covering the genetic map of six sex-linked genes on a fruit fly chromosome through classical linkage analysis (Morgan and Cattell 1912). The principles of genetic mapping and linkage analysis remain the same, but recent technological advances now facilitate the mapping of genes responsible for both simple and complex traits in a faster and more precise manner (Semagn et al. 2006). The genetic analysis of rust resistance genes in wheat involves crossing of the resistant genotype with a susceptible parent to produce segregating populations followed by screening against relevant pathogen isolates (Bariana and Bansal 2017). In the case of involvement of more than one gene in controlling resistance, the isolation of individual components and development of single locus segregating populations enables detailed characterization (Bariana and Bansal 2017).

Sears (1954) identified a series of monosomic plants lacking one of the homolog of 21 chromosomes individually and 41 telocentric chromosomes from the wheat genotype Chinese Spring. Endo and Gill (1996) later identified 436 chromosome deletions by Cbanding and developed the respective deletion stocks of common wheat. These pioneering studies facilitated the genetic and physical mapping of genes in the wheat genome. The chromosomal locations of several stripe rust resistance genes were determined through monosomic analysis using Sear's cytogenetic stocks (Bariana and McIntosh 1993; Bariana et al. 2002; Chen et al. 1996; Eriksen et al. 2004; McDonald et al. 2004; McIntosh et al. 1995). Molecular marker technologies have now largely replaced cytogenetic

${ }^{\dagger}$ Corresponding author: U. Bansal; Urmil.bansal@sydney.edu.au

Funding: This research was supported by the Australian Grains Research and Development Corporation (GRDC) through the Australian Cereal Rust Control Program, project no. US0063.

The authors declare no conflict of interest.

Accepted for publication 10 January 2019.

() 2019 The American Phytopathological Society techniques. Methods such as bulked segregant analysis (BSA; Michelmore et al. 1991), selective genotyping (SG; Xu et al. 2008), and whole genome scanning (Edae et al. 2016) using DNA marker technologies such as Infinium SNP bead chip arrays (Wang et al. 2014) and DArTseq (https://www.diversityarrays. com/technology-and-resources/dartseq/dart-application/) can be used to identify the chromosomal locations of resistance genes. Following the identification of markers linked with a target locus in BSA and SG, genotyping of the entire mapping population using the linked markers is performed to estimate genetic linkage and to detect close trait-marker associations (Collard et al. 2005). Molecular technologies facilitate faster and higher resolution mapping of rust resistance genes, compared with monosomic analysis (Bansal et al. 2011; Bariana et al. 2006, 2016; Basnet et al. 2013; Cheng et al. 2014; Dracatos et al. 2016; Feng et al. 2013; Herrera-Foessel et al. 2015; Lu et al. 2014; McIntosh et al. 2015 - 2016; Randhawa et al. 2014, 2015; Xu et al. 2013; Zhang et al. 2013; Zhou et al. 2014a, b).

The Australian Grains Gene Bank holds a collection of phenotypically diverse hexaploid wheat landraces originating from 32 different countries, known as the 'Watkins Collection'. This collection was compiled by A. E. Watkins in the 1920s to 1930s through the Board of Trade in London (Miller et al. 2000). These landraces harbor valuable genetic variation for resistance to biotic and abiotic stresses (Pasam et al. 2017). The common wheat landrace from China, Aus27430, showed resistance to predominant Australian Puccinia striiformis f. sp. tritici (Pst) pathotypes at the seedling stage and produced moderately resistant to moderately susceptible (MRMS) response at the adult plant stage. This study describes the inheritance and chromosomal location of the all stage stripe rust resistance carried by Aus27430 and its interaction with adult plant resistance (APR).

\section{Materials and Methods}

Plant materials. A single plant selection from the common wheat landrace Aus27430, obtained from the Australian Winter Cereal Collection (AWCC), Tamworth, Australia (now Australian Grains Gene Bank, Horsham), was crossed with the stripe rust susceptible genotype Avocet $\mathrm{S}(\mathrm{AvS})$, and an $\mathrm{F}_{5: 6}$ recombinant inbred line (RIL) population comprising 130 lines was developed. A set of 81 Australian 
wheat cultivars was used to test polymorphism of markers linked with the all stage resistance gene carried by Aus 27430 .

Greenhouse screening. The Aus27430/AvS $\mathrm{F}_{3}$ population was initially tested under greenhouse conditions against Pst pathotype $134 \mathrm{E} 16 \mathrm{~A}^{+} \mathrm{Yr} 17^{+} \mathrm{Yr} 27^{+}$to determine the mode of inheritance of resistance following the procedure outlined in McIntosh et al. (1995), and later the Aus27430/AvS RIL population was tested. Infection type (IT) variation was scored after 14 days of inoculation on a 0-4 scale described in McIntosh et al. (1995). More than usual necrosis or chlorosis was denoted by letters ' $\mathrm{N}$ ' and ' $\mathrm{C}$ ', respectively. Similarly, '-' and '+', respectively, explained slight variations in the expression of an IT. Twenty seeds of each $\mathrm{F}_{3}$ family and eight to 10 seeds of each RIL were sown in 9-cm-diameter plastic pots filled with potting mix ( $80 \%$ composted pine bark and $20 \%$ coarse sand) supplemented with the balanced fertilizer Aquasol (20 g/10 liters of water for 200 pots). The parents and susceptible genotype Morocco were included as controls. Seedlings were grown in microclimate rooms maintained at $20 \pm 2{ }^{\circ} \mathrm{C}$ until inoculated and were fertilized with urea 1 week after sowing at the same rate as Aquasol. At the two-tothree leaf stage, seedlings were inoculated using Pst pathotype 134 $\mathrm{E} 16 \mathrm{~A}^{+} \mathrm{Yr} 17^{+} \mathrm{Yr} 27^{+}$. The $\mathrm{F}_{3}$ families were classified homozygous resistant (HR; showing ITs 1 to 3c), segregating (SEG; ITs 1 to 23c and 3+), and homozygous susceptible (HS; IT 3+) based on seedling stripe rust responses. The RILs were categorized as HR and HS.

Tests were also conducted on the parents and four each HR and HS

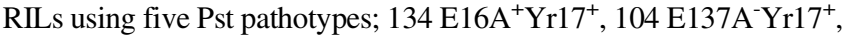

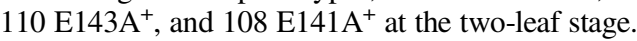

Field evaluation. Adult plant stripe rust response assessments were conducted at University of Sydney Plant Breeding Institute experimental sites in three replications in 2016 and two replications in 2018. The RIL population and parents were sown as eight to 10 seeds in hill plots. To facilitate rust infection in the field, a row of susceptible spreader was sown after every five hill plots horizontally and after every four rows vertically. Spreader rows were inoculated with a mixture of Pst pathotypes $110 \mathrm{E} 143 \mathrm{~A}^{+}$and $134 \mathrm{E} 16 \mathrm{~A}^{+} \mathrm{Yr} 17^{+} \mathrm{Yr} 27^{+}$ in the field.

Adult plant stripe rust response variation under field conditions was recorded using the 1-9 scale described by Bariana et al. (2007b), where $1=$ very resistant, $2=$ resistant, $3=$ resistant to moderately resistant, $4=$ moderately resistant, $5=$ moderately resistant to moderately susceptible, $6=$ moderately susceptible, $7=$ moderately susceptible to susceptible, $8=$ susceptible, and $9=$ very susceptible. Adult plant stripe rust responses were recorded when the susceptible parent AvS showed a score of 8. Preliminary observations were also made from booting stage to identify HS RILs.

Molecular analysis. DNA extraction. The modified CTAB method described in Bansal et al. (2014b) was used to extract DNA from 10-day-old leaves of each $\mathrm{F}_{3}$ family, RIL, and parent. The DNA samples were quantified using a Nanodrop ND-1000 Spectrophotometer (Nanodrop Technologies).

Molecular mapping. SG was performed on eight $\mathrm{HR}$ and eight $\mathrm{HS}$ Aus27430/AvS $\mathrm{F}_{3}$ families using the Illumina iSelect $90 \mathrm{~K}$ Infinium SNP genotyping array (Wang et al. 2014) to determine chromosomal location of the resistance locus.

Saturation of chromosome region on 6AS. Linked SNP markers from the Infinium genotyping array were converted to Kompetitive Allele-Specific PCR (KASP; LGC genomics, UK) assays and used to genotype Aus27430 and AvS. Polymorphic KASP markers were then assayed on the entire RIL population. In addition, six SSR markers: gwm459, gwm334, barc206, barc3, barc23, and gwm494, previously mapped on chromosome 6A (Somers et al. 2004), were used to confirm the location of YrAW5 on chromosome 6AS. Primer sequences of these SSR markers were taken from the GrainGenes 2.0 database (https://wheat.pw.usda.gov/).

PCR amplification of KASP markers. KASP assays were performed following protocols given at the LGC genomics website (https://www.lgcgroup.com/products/kasp-genotyping-chemistry/\#. WvKUz6SFOUk) using a CFX96 TouchTM real-time PCR detection system (BioRad, U.S.A.). The data were analyzed using Bio-Rad CFX Manager Software (BioRad) described in Bariana et al. (2016).
Genotyping for known APR gene markers. The Lr34/Yr18-linked marker csLV34 (Lagudah et al. 2006), Lr67/Yr46-linked SNP marker TM4 (Moore et al. 2015), Lr46/Yr29-linked marker Lr46_SNP1G22 (E. S. Lagudah, personal communication), and Sr2/Yr30-linked marker $\operatorname{cs} S r 2$ (Mago et al. 2011) were tested for the presence of these genes in Aus 27430 following protocols given in the respective publication.

Data analyses. $\chi^{2}$ analyses were conducted to test the goodness of fit of observed phenotypic segregation to the theoretically expected genetic ratios. Genetic linkage analysis was performed with Map Manager QTXb20 (Manly et al. 2001) using the Kosambi mapping function (Kosambi 1943). Linkage values with logarithm of odds (LOD) scores of 3.0 and above were considered statistically significant. Genetic maps were constructed using MapChart software (Voorrips 2002).

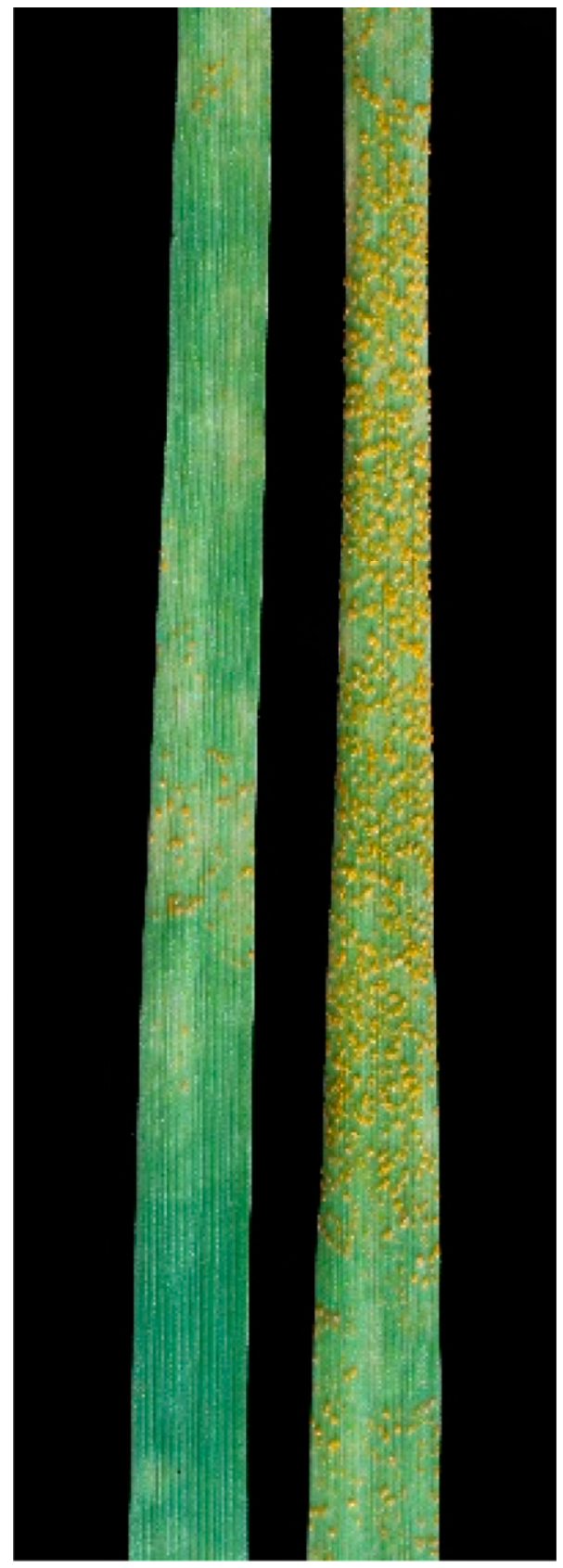

\section{Aus27430 Avocet S}

Fig. 1. Infection types produced by Aus $27430(1 \mathrm{C})$ and Avocet S (3+) when infected with Pst pathotype $134 \mathrm{E} 16 \mathrm{~A}+\mathrm{Yr} 17+\mathrm{Yr} 27+$ at the seedling stage. 


\section{Results}

Seedling tests. Aus27430 expressed ITs 1-c to 23c, whereas the susceptible parent AvS showed IT $3^{+}$(Fig. 1), when infected with Pst pathotype $134 \mathrm{E} 16 \mathrm{~A}+\mathrm{Yr} 17+\mathrm{Yr} 27+$. Tests on the $\mathrm{F}_{3}$ population showed monogenic segregation (22 HR: 68 SEG: $33 \mathrm{HS} ; \chi_{1: 2: 1}^{2}=$ 3.34 , nonsignificant at $P=0.05$ and $2 \mathrm{df}$ ), and the underlying resistance locus was temporarily named $Y r A W 5$. Stripe rust response variation among segregating $\mathrm{F}_{3}$ families indicated incomplete dominance of inheritance. The monogenic segregation for stripe rust resistance observed among the $\mathrm{F}_{3}$ families was confirmed on Aus27430/AvS RIL population (Table 1). The parents, four HR, four HS, and AvS were tested with other Pst pathotypes (Table 2). Aus27430 and HR lines produced low IT (1-c to 23c), and AvS and HS lines produced high IT (3+), indicating that $Y r A W 5$ is effective against all these Pst pathotypes.

Mapping of YrAW5. The iSelect 90K SNP arrays-based SG revealed association of 45 SNP markers from the short arm of chromosome 6A with YrAW5. KASP assays designed for the linked SNPs were tested on the parental genotypes Aus27430 and AvS. Seven KASP markers allowing unambiguous genotype calling were screened on the entire Aus27430/AvS RIL population. Six SSR markers previously mapped on chromosome $6 \mathrm{~A}$ also showed polymorphism between parents and were tested on the entire RIL population to confirm the chromosomal location of YrAW5. Markers KASP_3070 and gwm459 flanked YrAW5 at genetic distances of $2.7 \mathrm{cM}$ and $6.4 \mathrm{cM}$ distally and proximally, respectively (Fig. 2). The sequences of KASP markers used in the linkage map are listed in Table 3.

Detection of known APR. Parents Aus27430 and AvS were tested with markers linked to APR genes Lr34/Yrl8, Lr67/Yr46, $L r 46 / Y r 29$, and $S r 2 / Y r 30$. The presence of the $L r 34 / Y r 18$-linked 150-bp allele in Aus27430 suggested the presence of this gene, whereas amplification of products alternate to those linked with other APR genes indicated their absence.

Field tests. Under field conditions, Aus27430 showed a moderately resistant to moderately susceptible (MRMS) response (score 5), and the susceptible parent AvS was scored 8 to 9 (S-VS). Aus 27430 was observed to carry $\operatorname{Yr} 18$ based on the linked marker csLV34 and leaf tip necrosis associated with this gene. The entire Aus27430/AvS RIL population was tested with $c s L V 34$ and was partitioned into four genotypic classes; $Y r A W 5, Y r 18, Y r 18+Y r A W 5$, and no known gene (Table 4). The rust response data recorded on a 1-9 scale were converted into disease severity according to Bansal et al. (2014a). The RILs carrying YrAW5 (ITs 1c to 3c) and Yr18 singly did not differ significantly for mean rust severity under field conditions. RILs possessing $\mathrm{YrAW5}$ and $\mathrm{Yrl8}$ in combination resulted in

Table 1. Phenotypic distribution of Aus27430/AvS-derived RIL population when tested with Pst pathotype 134 E16A+Yr17+Yr27+ at the seedling stage under greenhouse conditions ${ }^{\mathrm{a}}$

\begin{tabular}{lcccc}
\hline & & \multicolumn{2}{c}{ Number of RILs } & \\
\cline { 3 - 4 } Response class & Response & Observed & Expected & $\boldsymbol{\chi}_{\mathbf{1 : 1}}^{\mathbf{2}}$ \\
\hline Seedling stage & Infection type & & & \\
Homozygous resistant & 1C to 3C & 57 & 65 & 0.98 \\
Homozygous susceptible & $33+$ to 3+ & 73 & 65 & 0.98 \\
Total & & 130 & 130 & 1.96 \\
\hline
\end{tabular}

a Table value of $\chi^{2}$ at $P=0.05$ and $1 \mathrm{df}$ is 3.841 .

Table 2. Infection types produced by parents, homozygous resistant, and homozygous susceptible lines against different Pst pathotypes

\begin{tabular}{lclcc}
\hline Pathotype & Aus27430 & HR lines & HS lines & Avocet S \\
\hline 134 E16A+Yr17+ & 2c & 1c to 23c & $3+$ & $3+$ \\
104 E137A-Yr17+ & 2c & 1-c to 23c & $3+$ & $3+$ \\
110 E143A+ & 23c & 2c to 23c & $3+$ & $3+$ \\
108 E141A+ & 23-c & 2c to 23c & $3+$ & $3+$ \\
\hline
\end{tabular}

significant reduction in average disease severity during the crop seasons $2016(28.3 \%)$ and 2018 (30\%) when compared with RILs that carried these genes singly or lacked both genes. The RILs carrying neither $\mathrm{Yr} 18$ nor $\mathrm{YrAW5}$ produced about 70 to $80 \%$ disease severities under field conditions. These results indicated that $Y r A W 5$ interacts additively with the APR gene $\operatorname{Yr} 18$ to lower disease severity.

Polymorphism of $\mathrm{YrAW5}$ linked molecular markers. Eightyone Australian wheat cultivars were tested with YrAW5 flanking markers KASP_3077 and gwm459. The marker KASP_3077 produced AvS haplotype (A:A) in 67 cultivars, whereas gwm459 produced the 126-bp specific to AvS in 80 cultivars. Gazelle was the only cultivar that carried the Aus 27430 allele at both markers, whereas, 13 cultivars carried the Aus 27430 allele for the KASP 3077 (Table 5). These results indicate that both markers can be used for marker-assisted breeding following polymorphism checks on potential parents.

\section{$6 \mathrm{~A}$}

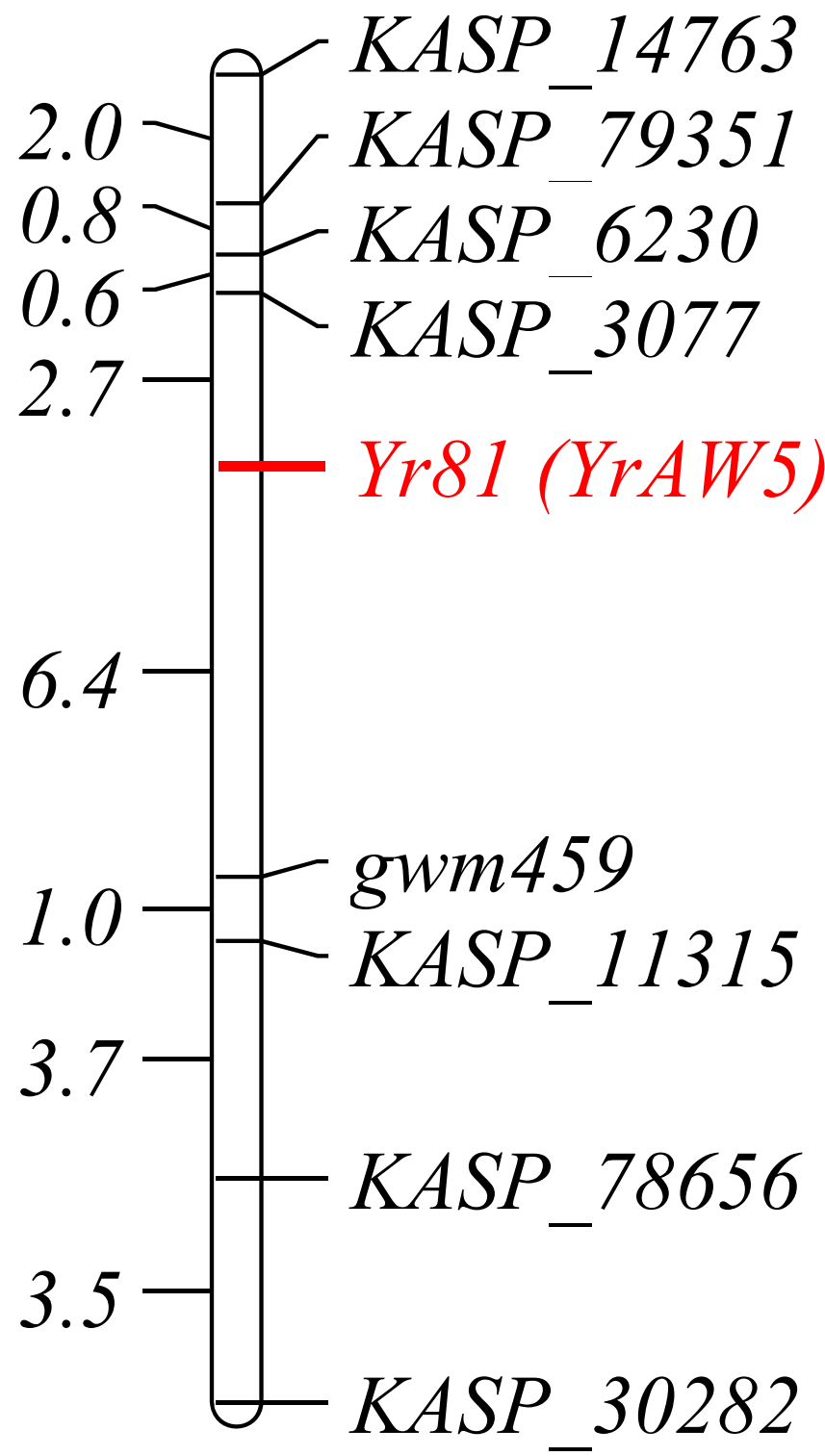

Fig. 2. Genetic linkage map of chromosome 6AS showing location of YrAW5 using KASP and SSR markers in a Aus27430/AvS RIL population. 


\section{Discussion}

Breeding for resistance to rust diseases in wheat is a continuous process, as the pathogens causing these diseases evolve to acquire virulence for resistance genes present in commercial cultivars (Bariana 2003; Bariana et al. 2007a; McIntosh and Brown 1997). The release of rust resistant wheat cultivars is important to reduce input costs and to increase profitability for growers. The uninterrupted release of rust resistance cultivars requires the continuous discovery and characterization of diverse sources of resistance. Genetic analysis of stripe rust resistance in the landrace genotype Aus27430 detected a putatively new stripe rust resistance gene, and it was temporarily named $Y r A W 5$. Several new rust resistance loci have been identified in pre-Green Revolution wheat genotypes in the last decade. Bansal et al. (2011) identified $\mathrm{Yr} 47$ in landraces Aus 28183 and Aus28187 using a procedure similar to that followed in this study. Other studies have resulted in the formal designations of Yr51 (Randhawa et al. 2014) and Yr57 (Randhawa et al. 2015) from the landrace Aus27858. Chhetri (2015) also identified a stripe rust resistance locus in landraces Aus27507 and Aus27894 from the Watkins Collection and named it $Y r 72$. Recently, Nsabiyera et al. (2018) identified an adult plant stripe rust resistance gene $\operatorname{Yr} 80$ in the landrace Aus27284. Similarly, Bansal et al. (2015) reported a new stem rust resistance locus Sr49 in Aus28011.

Stripe rust resistance from Aus27430 was located in the short arm of chromosome 6A using SG. Stripe rust resistance genes $\operatorname{Yr} 38$ (Marais et al. 2006) and Yr42 (Marais et al. 2009) are also located on chromosome 6A. These genes are present in translocated segments from Aegilops sharonensis (Yr38) and Ae. neglecta (Yr42) and produce lower infection types than that produced by $\operatorname{YrAW5}$. Hence, it is highly unlikely for $Y r A W 5$ to be $\operatorname{Yr} 38$ or $Y r 42$. Seven QTL for stripe rust resistance have been identified on chromosome $6 \mathrm{~A}$, including QYrex.wgp-6AS (linked markers gwp56, gwm334) in cultivar Express (Lin and Chen 2009), QYr.uga-6AS (wPt-671561,wPt-7840) in Pioneer 26R61 (Hao et al. 2011), QRYr6A0.2 (barc3, wPt-7063) in AvS (Lillemo et al. 2008), QRYr6A0.2 (gwm427, wmc256) in AvS (William et al. 2006), QRYr6A0.2 (wPt-0959, 378849) in AvS (Rosewarne et al. 2012), QRYr6A0.3 (wPt-1642, gwm617) in Platte (Vazquez et al. 2012), and $\operatorname{YrQ3}$ (gwm334, gwm169) in Xichang 76-9 (Cao et al. 2012). We compared the position of linked markers from above studies in Somers et al. (2004) and DArTseq map (https://www.diversityarrays.com/technology-and-resources/geneticmaps/). YrAw5 was mapped $6.5 \mathrm{cM}$ distal to $g w m 459$, whereas all other QTL linked markers were located proximal to gwm459 (Table 6), indicating that $Y r A W 5$ represents a new locus for all stage stripe rust resistance and was therefore formally designated $\operatorname{Yr} 81$.

This investigation characterized an all stage resistance gene $\operatorname{Yr} 81$ in Aus27430, and an attempt was made to uncover additional APR in this genotype. The presence of the APR gene $\mathrm{Yr} 18$ was observed in Aus27430. This gene interacted with $Y r 81$ to lower disease severity at the adult plant stage, suggesting that $\mathrm{Yr} 18$ is a good candidate for pyramiding to achieve durable control of stripe rust. It was surprising to note that responses of the ASR gene $\operatorname{Yr} 81$ and the APR gene $\operatorname{Yr} 18$ did not differ significantly. It could presumably be due to additional resistance present in the background as indicated by stripe rust severity variation of 40 to $100 \%$ among RILs lacking both $Y r 81$ and $Y r 18$. In another study, Chhetri et al. (2016) showed the additive interaction of adult plant resistance gene Yr46/Lr67/ Sr55 with the all stage resistance gene $\operatorname{Yr} 58$ (detected at the fourth leaf stage) in wheat genotype W195.

Various countries across Africa, Central Asia, and Europe are battling with new strains of stripe rust (http://www.fao.org/news/story/ en/item/469467/icode/). This is one of the most damaging diseases worldwide and can result in up to $60 \%$ yield loss (https://rusttracker. cimmyt.org/). Deployment of diverse sources of rust resistance in new wheat cultivars will help to avoid stripe rust epidemics in the future. Assessment of polymorphisms of trait-linked markers across target recurrent parents underpins their implementation in breeding program for marker assisted pyramiding (Bariana and Bansal 2017). The amplification of KASP_3077 and gwm459 alleles alternate to those linked with $\operatorname{Yr} 81$ in 82.7 and $98.8 \%$ of cultivars tested demonstrated their usefulness in marker-assisted selection

Table 4. Interaction of stripe rust resistance genes $\mathrm{YrAW5}$ and $\mathrm{Yr} 18$ among Aus27430/AvS F 6 RIL population under field conditions ${ }^{\mathrm{a}}$

\begin{tabular}{lccc}
\hline Gene & $\begin{array}{c}\text { No of } \\
\text { RILs }\end{array}$ & $\begin{array}{c}\text { Average } \\
\text { (3 replications) }\end{array}$ & $\begin{array}{c}\text { Average } \\
\text { (2 replications) 2018 }\end{array}$ \\
\hline YrAW5 & 24 & 43.07 & 50.79 \\
Yr18 & 37 & 38.61 & 42.19 \\
YrAW5+Yr18 & 33 & $28.55^{*}$ & $30.00^{*}$ \\
NIL & 36 & 71.11 & 81.81 \\
LSD (5\%) & & 7.10 & 10.71 \\
\hline
\end{tabular}

$\mathrm{a} *=$ Statistically significant.

Table 5. Australian cultivars tested for polymorphism with $Y r 81$-linked markers KASP_3077 and gwm459

\begin{tabular}{lcc}
\hline Cultivars & KASP_3077 & gwm459 (bp) \\
\hline Aus27430 & G:G & 132 \\
Avocet S & A:A & 126 \\
Gazelle & G:G & 132 \\
Beaufort, Emu Rock, Envoy, GBA Sapphire, & G:G & 126 \\
$\quad$ Mackellar, Mansfield, Naparoo, Orion, & & \\
Phantom, Scout, Sentinel, SF Adagio, & & \\
$\quad$ Yandanooka & \\
AGT Katana, Axe, Baxter, Bolac, Calingiri, & A:A & \\
$\quad$ Carnamah, Catalina, Chara, Cobra, Corack, & & \\
Correll, Crusader, Dart, Derrimut, & \\
Diamondbird, EGA Bonnie Rock, EGA & \\
Bounty, EGA Burke, EGA Gregory, EGA & \\
Wedgetail, EGA Wylie, Elmore CL PLus, & \\
Estoc, Forrest, Fortune, Gauntlet, Giles, & \\
Gladius, Grenade CL Plus, Harper, Impala, & \\
Impose CL Plus, Janz, Justica CL Plus, King & \\
Rock, Kord CL Plus, Kunjin, Lancer, Lang, & \\
Lincoln, Livingston, Mace, Magenta, & \\
Merinda, Merlin, Preston, SF Scenario, & \\
Shield, Spitfire, SQP Revenue, Strzelecki, \\
Sunco, Sunguard, Suntop, Sunvale, Sunvex, \\
Sunzell, Trojan, Ventura, Waagan, Wallup, \\
Wedin, Westonia, Wyalkatchem, Wylah, \\
Yitpi, Young \\
\hline
\end{tabular}

Table 3. Primer sequences for KASP markers used to map $\mathrm{YrAW5}$ on chromosome 6AS

\begin{tabular}{lclll}
\hline Marker & cM $^{\mathbf{a}}$ & \multicolumn{1}{c}{ Allele $\mathbf{1}^{\mathbf{b}}$} & \multicolumn{1}{c}{ Allele $\mathbf{2}^{\mathbf{c}}$} & \multicolumn{1}{c}{ Common/reverse } \\
\hline KASP_3077 & 4.7 & attccaaagtaattggcaacaggttca & ccaaagtaattggcaacaggttcg & tgtggagcgtgacaatgaggaagtt \\
KASP_79351 & 5.6 & ggctgaatcactggtggataacatt & gctgaatcactggtggataacatc & ggacttttagcagtaaacccatgatcaaa \\
KASP_6230 & 5.7 & aggagtatacatattgtcgtaaggatta & ggagtatacatatttgtcgtaaggatttg & gatacataggacagggtatcgccaa \\
KASP_14763 & 7.0 & ggtcctgtttagagtggagcgt & gtcctgtttagagtggagcgc & gcaaggagcgcaacctggactt \\
KASP_11315 & 13.5 & ccttcaacgacctgactgccaat & cttcaacgacctgactgccaag & cgaaggcgacgcggccgtt \\
KASP_78656 & 22.9 & gaagaattcgcatattcaggcgcaa & aagaattcgcatattcaggcgcag & tcgactctacccagcaaacttcctt \\
KASP_30282 & 33.3 & ggcggacgtggcaaggatgat & gcggacgtggcaaggatgac & cggagcgtggcaggcgcaa \\
\hline
\end{tabular}

${ }^{\mathrm{a}}$ Genetic map position of the SNP markers in the 90K snp assay (Wang et al. 2014).

${ }^{\mathrm{b}}$ A1 primer labeled with FAM: GAAGGTGACCAAGTTCATGCT.

c A2 primer labeled with HEX: GAAGGTCGGAGTCAACGGAT. 
Table 6. Markers linked with QTL located in the short arm of chromosome 6A

\begin{tabular}{llccc}
\hline QTL & Left marker & cM & Right marker & cM \\
\hline QYrex.wgp-6AS & gwp56 & Not known & gwm334 & 1 \\
QYr.uga-6AS & $w P t-671561^{\text {a }}$ & 6 & $w P t-7840$ & 23 \\
QRYr6A.2 & barc3 $^{\mathrm{b}}$ & 27 & $w P t-7063$ & - \\
QRYr6A.2 & gwm427 & 67 & $w m c 256$ & 80 \\
QRYr6A.2 & $w P t-0959$ & 14 & 378849 & - \\
QRYr6A.3 & $w P t-1642$ & 99 & gwm617 & 75 \\
YrQ3 & gwm334 & 1 & gwm169 & 81 \\
\hline
\end{tabular}

${ }^{a}$ Distance in cM is according to https://www.diversityarrays.com/technology -and-resources/genetic-maps/.

${ }^{\mathrm{b}}$ Distance in cM is according to Somers et al. (2004).

of this resistance source. Gazelle was the only cultivar that carried resistance-linked alleles for both markers. It is hard to prove the presence of $\mathrm{Yr} 81$ in Gazelle due to the presence of additional resistance inherited from parents K1056 (advanced breeding line), VPM1, and Vasco. Several stripe rust resistance gene-marker associations have been reported recently (Chhetri et al. 2016; McIntosh et al. 2015 - 2016; Nsabiyera et al. 2018; Qureshi et al. 2018; Randhawa et al. 2014, 2015) and are being used to deploy marker-tagged stripe rust resistance genes in Australian wheat backgrounds. Yr81 represents an additional intermediate-effect all stage resistance source to achieve genetic diversity for stripe rust resistance in future wheat cultivars.

\section{Acknowledgments}

The first author thanks Australia Awards for the scholarship.

\section{Literature Cited}

Bansal, U., Bariana, H., Wong, D., Randhawa, M., Wicker, T., Hayden, M., and Keller, B. 2014a. Molecular mapping of an adult plant stem rust resistance gene $\operatorname{Sr} 56$ in winter wheat cultivar Arina. Theor. Appl. Genet. 127: 1441-1448.

Bansal, U. K., Forrest, K. L., Hayden, M. J., Miah, H., Singh, D., and Bariana, H. S. 2011. Characterisation of a new stripe rust resistance gene $\mathrm{Yr} 47$ and its genetic association with the leaf rust resistance gene Lr52. Theor. Appl. Genet. 122:1461-1466.

Bansal, U. K., Kazi, A. G., Singh, B., Hare, R. A., and Bariana, H. S. 2014b. Mapping of durable stripe rust resistance in a durum wheat cultivar Wollaroi. Mol. Breed. 33:51-59.

Bansal, U. K., Muhammad, S., Forrest, K. L., Hayden, M. J., and Bariana, H. S. 2015. Mapping of a new stem rust resistance gene $\mathrm{Sr} 49$ in chromosome 5B of wheat. Theor. Appl. Genet. 128:2113-2119.

Bariana, H., Forrest, K., Qureshi, N., Miah, H., Hayden, M., and Bansal, U. K. 2016. Adult plant stripe rust resistance gene $Y r 71$ maps close to $L r 24$ in chromosome 3D of common wheat. Mol. Breed. 36:98.

Bariana, H. S. 2003. Breeding for disease resistance. Pages 244-253 in: Encyclopedia of Applied Plant Sciences. B. Thomas, B. G. Murray, and D. J. Murphy, eds. Elsevier Ltd.

Bariana, H. S., and Bansal, U. K. 2017. Breeding for disease resistance A2 Thomas, Brian. Pages 69-76 in: Encyclopedia of Applied Plant Sciences, 2nd ed. B. G. Murray, and D. J. Murphy, eds. Academic Press, Oxford.

Bariana, H. S., Brown, G. N., Ahmed, U. N., Khatkar, S., Conner, L. R., Wellings, R. C., Haley, S., Sharp, J. P., and Laroche, A. 2002. Characterisation of Triticum vavilovii-derived stripe rust resistance using genetic, cytogenetic and molecular analyses and its marker-assisted selection. Theor. Appl. Genet. 104:315-320.

Bariana, H. S., Brown, G. N., Bansal, U. K., Miah, H., Standen, G. E., and Lu, M. 2007a. Breeding triple rust resistant wheat cultivars for Australia using conventional and marker-assisted selection technologies. Aust. J. Agric. Res. 58:576.

Bariana, H. S., and McIntosh, R. A. 1993. Cytogenetic studies in wheat. XV. Location of rust resistance genes in VPMl and their genetic linkage with other disease resistance genes in chromosome 2A. Genome 36:476-482.

Bariana, H. S., Miah, H., Brown, G. N., Willey, N., and Lehmensiek, A. 2007b. Molecular mapping of durable rust resistance in wheat and its implication in breeding. In: H. T. Buck, J. E. Nisi, and N. Salomon, ed. Proc $7^{\text {th }}$ Int. Wheat Conf. Springer, Mar Del Plata, Argentina.

Bariana, H. S., Parry, N., Barclay, I. R., Loughman, R., McLean, R. J., Shankar, M., Wilson, R. E., Willey, N. J., and Francki, M. 2006. Identification and characterization of stripe rust resistance gene $Y r 34$ in common wheat. Theor. Appl. Genet. 112:1143-1148
Basnet, B. R., Singh, R. P., Ibrahim, A. M. H., Herrera-Foessel, S. A., HuertaEspino, J., Lan, C., and Rudd, J. C. 2013. Characterization of Yr54 and other genes associated with adult plant resistance to yellow rust and leaf rust in common wheat Quaiu 3. Mol. Breed. 33:385-399.

Cao, X., Zhou, J., Gong, X., Zhao, G., Jia, J., and Qi, X. 2012. Identification and validation of a major quantitative trait locus for slow-rusting resistance to stripe rust in wheat. J. Integr. Plant Biol. 54:330-344.

Chen, X., Jones, S. S., and Line, R. F. 1996. Chromosomal location of genes for resistance to Puccinia striiformis in seven wheat cultivars with resistance genes at the Yr3 and Yr4 loci. Phytopathology 86:1228-1233.

Cheng, P., Xu, L. S., Wang, M. N., See, D. R., and Chen, X. M. 2014. Molecular mapping of genes Yr64 and Yr65 for stripe rust resistance in hexaploid derivatives of durum wheat accessions PI 331260 and PI 480016. Theor. Appl. Genet. 127:2267-2277.

Chhetri, M. 2015. Molecular mapping and genetic characterization of rust resistance in wheat. Ph.D. thesis. University of Sydney, Sydney, Australia.

Chhetri, M., Bansal, U., Toor, A., Lagudah, E., and Bariana, H. 2016. Genomic regions conferring resistance to rust diseases of wheat in a W195/BTSS mapping population. Euphytica 209:637-649.

Collard, B. C. Y., Jahufer, M. Z. Z., Brouwer, J. B., and Pang, E. C. K. 2005. An introduction to markers, quantitative trait loci (QTL) mapping and markerassisted selection for crop improvement: The basic concepts. Euphytica 142: 169-196.

Dracatos, P. M., Zhang, P., Park, R. F., McIntosh, R. A., and Wellings, C. R. 2016. Complementary resistance genes in wheat selection 'Avocet R' confer resistance to stripe rust. Theor. Appl. Genet. 129:65-76.

Edae, E. A., Olivera, P. D., Jin, Y., Poland, J. A., and Rouse, M. N. 2016. Genotype-by-sequencing facilitates genetic mapping of a stem rust resistance locus in Aegilops umbellulata, a wild relative of cultivated wheat. BMC Genomics 17:1039.

Endo, T. R., and Gill, B. S. 1996. The deletion stocks of common wheat. J. Hered 87:295-307.

Eriksen, L., Afshari, F., Christiansen, M. J., McIntosh, R. A., Jahoor, A., and Wellings, C. R. 2004. Yr32 for resistance to stripe (yellow) rust present in the wheat cultivar Carstens V. Theor. Appl. Genet. 108:567-575.

Feng, J., Chen, G., Wei, Y., Liu, Y., Jiang, Q., Li, W., Pu, Z., Lan, X., Dai, S., and Zheng, Y. 2013. Identification and genetic mapping of a recessive gene for resistance to stripe rust in wheat line LM168-1. Mol. Breed. 33:601-609.

Hao, Y., Chen, Z., Wang, Y., Bland, D., Buck, J., Brown-Guedira, G., and Johnson, J. 2011. Characterization of a major QTL for adult plant resistance to stripe rust in US soft red winter wheat. Theor. Appl. Genet. 123: 1401-1411.

Herrera-Foessel, S. A., Singh, R. P., Lan, C. X., Huerta-Espino, J., Calvo-Salazar, V., Bansal, U. K., Bariana, H. S., and Lagudah, E. S. 2015. Yr60, a gene conferring moderate resistance to stripe rust in wheat. Plant Dis. 99:508-511.

Kosambi, D. D. 1943. The estimation of map distances from recombination values. Ann. Eugen. 12:172-175.

Lagudah, E. S., McFadden, H., Singh, R. P., Huerta-Espino, J., Bariana, H. S., and Spielmeyer, W. 2006. Molecular genetic characterization of the Lr34/Yrl8 slow rusting resistance gene region in wheat. Theor. Appl. Genet. 114:21-30.

Lillemo, M., Asalf, B., Singh, R. P., Huerta-Espino, J., Chen, X. M., He, Z. H., and Bjornstad, A. 2008. The adult plant rust resistance loci $\mathrm{Lr} 34 / \mathrm{Yr} 18$ and $\mathrm{Lr} 46 /$ Yr29 are important determinants of partial resistance to powdery mildew in bread wheat line Saar. Theor. Appl. Genet. 116:1155-1166.

Lin, F., and Chen, X. M. 2009. Quantitative trait loci for non-race-specific, hightemperature adult-plant resistance to stripe rust in wheat cultivar Express Theor. Appl. Genet. 118:631-642.

Lu, Y., Wang, M., Chen, X., See, D., Chao, S., and Jing, J. 2014. Mapping of Yr62 and a small-effect QTL for high-temperature adult-plant resistance to stripe rust in spring wheat PI 192252. Theor. Appl. Genet. 127:1449-1459.

Mago, R., Brown-Guedira, G., Dreisigacker, S., Breen, J., Jin, Y., Singh, R., Appels, R., Lagudah, E. S., Ellis, J., and Spielmeyer, W. 2011. An accurate DNA marker assay for stem rust resistance gene $\mathrm{Sr} 2$ in wheat. Theor. Appl. Genet. 122:735-744.

Manly, K. F., Cudmore, R. H., Jr., and Meer, J. M. 2001. Map Manager QTX, cross-platform software for genetic mapping. Mamm. Genome 12:930-932.

Marais, F., Marais, A., McCallum, B., and Pretorius, Z. 2009. Transfer of leaf rust and stripe rust resistance genes and from Req. ex Bertol. to Common Wheat Crop Sci. 49:871.

Marais, G. F., McCallum, B., and Marais, A. S. 2006. Leaf rust and stripe rust resistance genes derived from Aegilops sharonensis. Euphytica 149:373-380.

McDonald, D. B., McIntosh, R. A., Wellings, C. R., Singh, R. P., and Nelson, J. C. 2004. Cytogenetical studies in wheat XIX. Location and linkage studies on gene Yr27 for resistance to stripe (yellow) rust. Euphytica 136:239-248.

McIntosh, R., Dubcovsky, J., Rogers, W., Morris, C., Appels, R., and Xia, X. 2015 2016. Catalogue of gene symbols for wheat: 2015 - 2016 Supplement. https:// shigen.nig.ac.jp/wheat/komugi/genes/macgene/supplement2015.pdf.

McIntosh, R., Wellings, C., and Park, R. F. 1995. Wheat rusts: An atlas of resistance genes. CSIRO Publishing, Australia.

McIntosh, R. A., and Brown, G. N. 1997. Anticipatory breeding for resistance to rust diseases in wheat. Annu. Rev. Phytopathol. 35:311-326.

Michelmore, R. W., Paran, I., and Kesseli, R. V. 1991. Identification of markers linked to disease-resistance genes by bulked segregant analysis: A rapid 
method to detect markers in specific genomic regions by using segregating populations. Proc. Natl. Acad. Sci. USA 88:9828-9832.

Miller, T. E., Reader, S. M., and Ambrose, M. J. 2000. The Watkins collection. Annu. Wheat Newsl. 46:72.

Moore, J. W., Herrera-Foessel, S., Lan, C., Schnippenkoetter, W., Ayliffe, M., Hueta-Espino, J., Lillemo, M., Viccars, L., Pariyannan, S., Kong, X., Speilmeyer, W., Talbot, M., Bariana, H., Patrick, J. W., Dodds, P., Singh, R., and Lagudah, E. 2015. A recently evolved hexose transporter variant confers resistance to multiple pathogens in wheat. Nat. Genet. 47:1494-1498.

Morgan, T. H., and Cattell, E. 1912. Data for the study of sex-linked inheritance in Drosophila. J. Exp. Zool. 13:79-101.

Nsabiyera, V., Bariana, H. S., Qureshi, N., Wong, D., Forrest, K. L., Hayden, M. J., and Bansal, U. K. 2018. Characterisation and molecular mapping of adult plant stripe rust resistance in wheat accession Aus27284. Theor. Appl. Genet. 131: 1459-1467.

Pasam, R., Bansal, U. K., Daetwyler, H., Forrest, K. L., Wong, D., Petkowski, J., Willey, N., Randhawa, M., Chhetri, M., Hanif, M., Tibbits, J., Bariana, H., and Hayden, M. J. 2017. Detection and validation of genomic regions associated with resistance to rust diseases in a worldwide hexaploid wheat landrace collection using BayesR and Mixed Linear Model approaches. Theor. Appl. Genet. 130:777-793.

Qureshi, N., Bariana, H., Zhang, P., McIntosh, R., Wong, D., Shankar, M., Hayden, M. J., Dubcovsky, J., and Bansal, U. 2018. Genetic relationship of stripe rust resistance genes $\mathrm{Yr} 34$ and $\mathrm{Yr} 48$ in wheat and identification of linked KASP markers. Plant Dis. 102:413-420.

Randhawa, M., Bansal, U., Valarik, M., Klocova, B., Dolezel, J., and Bariana, H. 2014. Molecular mapping of stripe rust resistance gene $\mathrm{Yr} 51$ in chromosome 4AL of wheat. Theor. Appl. Genet. 127:317-324.

Randhawa, M. S., Bansal, U., Mago, R., and Bariana, H. 2015. Yr57 - Mapping of a new stripe rust resistance locus Yr57 on chromosome 3BS of wheat. Mol. Breed. 35:65.

Rosewarne, G. M., Singh, R. P., Huerta-Espino, J., Herrera-Foessel, S. A., Forrest, K. L., Hayden, M. J., and Rebetzke, G. J. 2012. Analysis of leaf and stripe rust severities reveals pathotype changes and multiple minor QTLs associated with resistance in an Avocet $\times$ Pastor wheat population. Theor. Appl. Genet. 124: 1283-1294.

Sears, E. R. 1954. The Aneuploids of common wheat. University of Missouri, College of Agriculture. Agric. Exp. Stn. Res. Bull. 572.
Semagn, K., Bjørnstad, A., and Ndjiondjop, M. N. 2006. Principles, requirements and prospects of genetic mapping in plants. Afr. J. Biotechnol. 5(25): 2569-2587.

Somers, D. J., Isaac, P., and Edwards, K. 2004. A high-density microsatellite consensus map for bread wheat (Triticum aestivum L.). Theor. Appl. Genet. 109:1105-1114.

Vazquez, M. D., Peterson, C. J., Riera-Lizarazu, O., Chen, X., Heesacker, A. Ammar, K., Crossa, J., and Mundt, C. C. 2012. Genetic analysis of adult plant, quantitative resistance to stripe rust in wheat cultivar 'Stephens' in multi-environment trials. Theor. Appl. Genet. 124:1-11.

Voorrips, R. 2002. MapChart: Software for the graphical presentation of linkage maps and QTLs. J. Hered. 93:77-78.

Wang, S., Wong, D., Forrest, K., Allen, A., Chao, S., Huang, B. E., Maccaferri, M., Salvi, S., Milner, S. G., and Cattivelli, L. 2014. Characterization of polyploid wheat genomic diversity using a high-density 90000 single nucleotide polymorphism array. Plant Biotechnol. J. 12:787-796.

William, H. M., Singh, R. P., Huerta-Espino, J., Palacios, G., and Suenaga, K. 2006. Characterization of genetic loci conferring adult plant resistance to leaf rust and stripe rust in spring wheat. Genome 49:977-990.

Xu, L. S., Wang, M. N., Cheng, P., Kang, Z. S., Hulbert, S. H., and Chen, X. M 2013. Molecular mapping of $\mathrm{Yr} 53$, a new gene for stripe rust resistance in durum wheat accession PI 480148 and its transfer to common wheat. Theor. Appl. Genet. 126:523-533.

$\mathrm{Xu}$, Y., Wang, J., and Crouch, J. H. 2008. Selective genotyping and pooled DNA analysis: An innovative use of an old concept. In: Recognizing Past Achievement, Meeting Future Needs. Proc. $5^{\text {th }}$ Int. Crop Sci. Congr. 3-18 April 1 2008, Jeju, Korea.

Zhang, X., Kang, Z., Han, D., Zeng, Q., Duan, Y., Yuan, F., Shi, J., Wang, Q., Wu, J., and Huang, L. 2013. Fine mapping of wheat stripe rust resistance gene $\operatorname{Yr} 26$ based on collinearity of wheat with Brachypodium distachyon and rice. PLoS One 8:e57885.

Zhou, X. L., Han, D. J., Chen, X. M., Gou, H. L., Guo, S. J., Rong, L., Wang, Q. L., Huang, L. L., and Kang, Z. S. 2014a. Characterization and molecular mapping of stripe rust resistance gene $\mathrm{Yr} 61$ in winter wheat cultivar Pindong 34. Theor. Appl. Genet. 127:2349-2358.

Zhou, X. L., Wang, M. N., Chen, X. M., Lu, Y., Kang, Z. S., and Jing, J. X. 2014b. Identification of Yr59 conferring high-temperature adult-plant resistance to stripe rust in wheat germplasm PI 178759. Theor. Appl Genet. 127:935-945. 